This is the accepted version of the following article:

\title{
MATRIX THINKING: AN ADAPTATION AT THE FOUNDATION OF HUMAN SCIENCE, RELIGION, AND ART
}

by Margaret Boone Rappaport, Christopher J. Corbally,

in Zygon: Journal of Religion and Science, vol. 50, no. 1 (March 2015), pp. 84- 112, which has been published in final form at https://authorservices.wiley.com/api/pdf/fullArticle/12879196.

This article may be used for non-commercial purposes in accordance with the Wiley SelfArchiving Policy [https://authorservices.wiley.com/author-resources/JournalAuthors/licensing-open-access/open-access/self-archiving.html]

\begin{abstract}
.
Intrigued by Robinson and Southgate’s 2010 work on "entering a semiotic matrix," we expand their model to include the juxtaposition of all signs, symbols, and mental categories, and to explore the underpinnings of creativity in science, religion, and art. We rely on an interdisciplinary review of human sentience in archaeology, evolutionary biology, the cognitive science of religion, and literature, and speculate on the development of sentience in response to strong selection pressure on the hominin evolutionary line, leaving us the "lone survivors" of complex, multiple lines of physical and cultural evolution. What we call Matrix Thinking - the creative driver of human sentience-has important cognitive and intellectual features, but also equally important characteristics traced to our intense sociability and use of emotionality in vetting rational models. Scientist, theologian, and artist create new cultural knowledge within a social context even if alone. They are rewarded by emotional validation from group members, and guided by the ever present question, "Does it feel right?"
\end{abstract}

Keywords:

aesthetics; anthropology; creativity; emotion; evolutionary biology; Matrix Thinking; semiotics; sentience; theology and science

Margaret Boone Rappaport is an anthropologist, biologist, and co-founder of the Human Sentience Project, Tucson, AZ, USA; e-mail: msbrappaport@aol.com.

Christopher J. Corbally, SJ, is an astronomer with the Vatican Observatory and Department of Astronomy, University of Arizona, Tucson, AZ, USA and co-founder of the Human Sentience Project; e-mail: corbally@as.arizona.edu. 
MATRIX THINKING:

AN ADAPTATION AT THE FOUNDATION

OF HUMAN SCIENCE, RELIGION, AND ART

Margaret Boone Rappaport and Christopher Corbally

\section{PRELUDE TO A CONSTRUCT}

In Zygon - this venue where science and religion seek common ground - we found a paper that was seminal in our conceptualization of a proposed construct - Matrix Thinking - and our future plans for The Human Sentience Project. ${ }^{1}$ Many writers have reacted to Andrew Robinson and Christopher Southgate's 2010 paper on "Semiotics as a Metaphysical Framework for Christian Theology.” We are not exceptions, and in reading their work, we stumbled upon "a gem" in their model of "entering a semiotic matrix" (2010, 702; Robinson 2010). We had become convinced through our own backgrounds, which spanned from anthropology to astronomy and from biology to theology, that science, religion, and art had similar roots. When we looked into our own and each other's pursuits, both intellectual and artistic (in sculpture, poetry, and music), we perceived no disunity. Something was the same about all of our activities. Was this an illusion? No, but the reason was not clear until we finished Robinson and Southgate's paper, especially the section on "Semiotics and Anthropology," and kept on reading in the fields of archaeology, evolutionary biology and psychology, and the cognitive science of religion.

Robinson and Southgate came close in their thinking to some of the latest insights from evolutionary science, especially the archaeology of early humans and the emergence of "modern thinking” on the hominin ${ }^{2}$ line of evolution leading to anatomically modern humans (AMH). ${ }^{3}$ They write, "It is often said that human distinctiveness lies in our capacity for using language,” and they point to Deacon's extension of this to “our competence in using Peircean symbols (signs whose relation to their object is given by a convention)" (2010, 701; Deacon 2003). Robinson and Southgate then go further, and it is important to note how they go: Not by glossing over the characteristic features of the hominin evolutionary line and pointing generally to our capacity for language and symbol use, but by looking into the mechanics of how the use of language and symbols might be accomplished to create new ideas. The source of their insight was C. S. Peirce's taxonomy of signs (1931-1935). In retrospect, Matrix Thinking was a construct sparked by two sources in widely divergent fields: first, from their article exploring C.S. Peirce's work in semiotics and applying it to theology; and second, from archaeologist Thomas Wynn's and psychologist Frederick Coolidge’s paper on “working memory” (2011). 
Matrix Thinking, which is defined fully in the next section, lies within a context of evolutionary biology, and it is based on our knowledge of the latest archaeological finds. The latter suggest that modern human thinking developed as far back as the Middle Stone Age in Africa, some 200,000 to 300,000 years ago, in sites where the earliest signs of science, religion, and art are found.

Our main goal in this work and its sequel is to introduce Matrix Thinking as a capacity responsible for the fashioning of new ideas. We find that Matrix Thinking is a construct whose time has come because aspects of it appear in many branches of the sciences and humanities. We believe that it deserves careful testing and analysis to address problems both philosophical and pragmatic, which face the human population at the beginning of the twenty-first century. We propose Matrix Thinking as one of the foundations on which humans build new cultural knowledge in science, religion, and art - those endeavors which make us the most modern and the most human of all.

Our model owes much to Robinson and Southgate’s formulation of "entering a semiotic matrix," and in this paper we explain how their "gem" led to the proposed construct of Matrix Thinking. The following passages from their discussion of "Semiotics and Anthropology" suggest an important mechanism at the foundation of human thought. [This quote is used again in Part 4, in the derivation of a new metaphor from an old one.]

This threshold was the discovery of how to creatively juxtapose signs of different types, particularly how to combine symbols with different kinds of icon. The type of cognitive process we are referring to is that familiar to us in the use of diagrams and metaphors, both of which are kinds of icon that depend on symbolic representations and are in turn capable of generating new conceptual knowledge. Crossing this semiotic thresholdentering the semiotic matrix - opened up the possibility of art (iconic qualisigns made in the context of symbolic understanding) and ritual (iconic legisigns giving access to new conceptualizations). The important point is that these juxtapositions of signs would have consisted not merely of sequential combinations of signs but of a creative dialectic between different types of sign... One may speculate further that perhaps the Neanderthals were able to imitate the products of this dialectic, such as burial of the dead (Mithen 1996, 135-36), without ever "getting” the cognitive trick. $(2010,702)$

It was logical for us to extend juxtaposition of different signs to juxtaposition of all types of signs - symbols, indices, and icons, to use Peirce's taxonomy - and, to include other mental categories and experiences, as well. We did not feel constrained to view "a semiotic matrix" as a vehicle only for semiotic analysis. We stretched it, and in doing so, we came to propose a different kind of use for Robinson and Southgate's original model.

Our extension of their process of "entering a semiotic matrix" was necessary for our requirement that creative cognitive processes apply to all human "Advanced Domains 
of Thought” (science, religion, and art), because, in being human enterprises, those fields take place not just within an intellectual and cognitive world, but within a social and emotional world, as well. The Advanced Domains require the most intense concentration and the most difficult juxtaposition of symbolic structures held in the mind concurrently. Not surprisingly, the creations derived in the Advanced Domains are the most thoroughly informed by human sociability and emotionality. We concluded that our construct of Matrix Thinking could not be confined to signs, whether the same or a different type, but must be expanded to include all types of signs, symbolic structures , models, relationships, perceptions, emotions, and different combinations of each of these, too.

This notion blossomed when we read the work of archaeologist Thomas Wynn and psychologist Frederick Coolidge on "working memory” and "enhanced working memory" (2011). Those concepts provided both a physical and a mental model in which an extended "entering a semiotic matrix" process would work among early and modern humans. The work of Robinson and Southgate, and Wynn and Coolidge imply a "mental space in which to do work." We were becoming convinced that modern faculties lying at the foundation of the Advanced Domains of Thought (science, religion, and art) involved more than symbol and language use, and that they were, first and foremost, genetically based and heritable abilities.

\section{DEFINITIONS}

We hypothesize a human cognitive capacity named "Matrix Thinking," which developed early in the evolution of the genus Homo as a bona fide, genetically based, biological adaptation that underlies human creativity in science, art, and religion, and perhaps other cognitive domains, which involve the manipulation of complex symbolic structures and the creation of new cultural knowledge. We find support for the adaptive nature of Matrix Thinking in its pervasiveness, flexibility, internal coherence and complexity, ubiquity in all human populations, the ease with which it is acquired by children, and its antiquity in the deepening archaeological record in Africa. Matrix Thinking has, upon close inspection (in this paper's sequel), that important mark of “special design,” which characterizes true adaptations (Simpson \& Campbell 2005, 126). Eventually, we believe that cognitive facilities such as Matrix Thinking will be associated with specific genes and gene combinations, such as the HAR1 gene (linked to cerebral cortex development), the ASPM gene (linked to brain size evolution), and the FOXP2 (linked to speech organ development). However, identification of these genes in, for example, a comparison of the human and chimpanzee genomes, is just the barest beginning of a solution to the perennial puzzle, "What makes us different?" (Pollard 2013, 34; CSAC 2005).

When we review related concepts such as "working memory" and "enhanced working memory” (Wynn \& Coolidge 2011), “conceptual blending” (Fauconnier \& Turner 2002), Deacon's work on the "co-evolution” of language and the human brain (2011; 1997), Dunbar’s “social brain hypothesis” (2009; 1998), and Pagel’s “human 
social mind" (2012), we find much to enrich our work. However, none of these constructs is exactly isometric to the capacity that we suggest arose among our distant ancestors and that is responsible, we believe, for the oldest indications of modern thinking in science, religion, and art. Archaeological reports describe paint production, decorative beads, complex tools, and other examples of the external storage of culture, in Middle Stone Age sites as old as 200,000 years, in Africa (Stringer 2012; Wadley et al. 2011; Wadley 2001; Henshilwood, D’Errico, \& Watts 2009; D’Errico, Henshilwood et al. 2005).

We define Matrix Thinking as a faculty that allows the dynamic juxtaposition of complex symbolic structures, gradients, analogies, narratives, and entire paradigms in a mind that can hold them in the consciousness and focus upon their differences, similarities, and connections for extended periods of time without distraction (a condition specified in Wynn \& Coolidge 2011). Fully functioning Matrix Thinking may be one of the most recent major cognitive acquisitions in human biological evolution. Whereas Matrix Thinking is almost surely based upon genetic changes that resulted from the pressures of natural selection, it allows, or more accurately, facilitates and even encourages human cultural evolution through "scaffolding" between generations and "cultural ratcheting" within them (Caporael et al. 2013; Dean et al. 2012). We suggest that Matrix Thinking emerged toward the end of an era in which most change among early humans was biological, and on the cusp of an era in which cultural evolution took over to make humans adaptable to every environment on Earth and its Moon, so far.

We propose that Matrix Thinking is the creative driver of human sentience, which we understand to be that fully self-aware quality of thinking for intelligent, intensely social and emotional early hominins of the genus Homo who arose between 200,000 and 300,000 years ago, probably in East Africa (Brooks 2008; Brooks et al. 2006), and all human populations since that time. Matrix Thinking is a recent development in the course of Big History, which began with the Big Bang. It is the only level of complexity that allows Big History to look back upon itself reflexively and understand itself (Corbally \& Rappaport 2013).

Matrix Thinking often makes use of the flexibility and compressed nature inherent to language symbols (and icons and indices), as well as the compressed nature of shapes, colors, movements, and relationships in primary process thinking. The manipulations of Matrix Thinking are often expressed most easily through language and mathematics, although it does not necessarily need language or mathematics. Symbolic structures that are analyzed, de-constructed, and then applied to a different topic in the course of Matrix Thinking can be expressed through the movements, shapes, colors, relationships, and feelings that we glimpse in our dreams and other instances of primary process thinking (Holt 2008).

We are, according to Pagel (2012), "wired for culture” with a brain that takes full advantage of our intense sociability and conversely, contributes to social cooperation and stability. And, while that wiring probably allows for much, much more, it surely must include a facility like Matrix Thinking because cultural creativity, especially in science, religion, and art, is ubiquitous in human societies. The results of Matrix Thinking are all 
around us, perhaps most evident in the easy installation of unique instances in the linguistic, social, and philosophical structures that make our experience meaningful. For example, when a lone human is discovered, injured and dazed, and that human is taken into a new society to heal, there is little problem in eventually deciding where he fits in the social structure, whom he is allowed to marry, and the village sector to which he most owes his allegiance. The kinship organization of the receiving group provides an available role and identity, with just a little stretching of the rules.

So-called fictive kinship is easy work for the human mind because of capacities such as Matrix Thinking. However, the examples that are responsible for the great leaps in human intuition and discovery do not occur very frequently. "Enhanced working memory" (Wynn \& Coolidge 2011) is the closest construct to Matrix Thinking that we can find in the literature, and as it is defined, it does not occur all that often. "It [EWM] requires a lot of effort... If we don't have to use it, we don't” (Wynn 2012). Therefore, it seems entirely possible that a facility such as Matrix Thinking is used most effectively by particularly intelligent or talented individuals within a social group. This, along with the fact that human populations were thinly distributed until very recently, would help to explain the slow tempo of cultural evolution until about 35,000 years ago. If Matrix Thinking is a cognitive capacity that is the creative driver of human sentience, and if it is the "great leap maker," then it would not be expected to occur in stellar form very often.

Because language is so useful in manipulating symbolic structures, Deacon's extensive work on the mutual facilitation of language and the increasing size and complexity of the human brain supports, and is supported by, a construct like Matrix Thinking. Deacon holds that our language capacity and explosive brain development evolved in tandem. We suggest that this is true partly because linguistic symbols are so nicely compact in encapsulating meaning, so malleable and therefore useful in Matrix Thinking. Their recombination is virtually infinite, like language units such as phonemes and morphemes, themselves, are re-combinable in almost endless variation.

When Deacon (2011, 397) cogently explicates C.S. Peirce’s 1931-35 work in semiotics, he suggests a possible window onto the sequencing of human cognitive evolution from icon use to index use to symbol use, and from qualisign assignation of meaning, to sinsign assignation, to legisign assignation. There is inherently an ordering to the categories of sign use and meaning assignation that Peirce teases apart so finely. In pointing this out, Deacon helps us to imagine a chronology of hominin development. He writes, "There is an asymmetric dependency in both the vertical and horizontal dimensions of the chart, with positions designated by a 1 being more basic and 3 being most derived...” We suggest that this ordering mimics, or parallels, hominin evolution. While it is entirely possible that evolution occurred very rapidly because of the usefulness of Matrix Thinking to survival, it is also possible that there were stages in its emergence that differentiated populations of early humans, and gave some a needed edge in the fight for life on the African savannah, alongside prehistoric lakes, with other hominins before and after they left Africa, and in competition with fierce predators that some humans would eventually displace. 
We propose that Matrix Thinking requires a certain minimal brain capacity, both in size and complexity, including connections between parts of the brain that guide social and emotional functioning, and the more advanced prefrontal cortex used in reasoning and planning, where the so-called “executive functions" are located (Stringer 2012; Evans et al. 2006; Evans et al. 2005; Dunbar 1998; Deacon 1997). Matrix Thinking arose among intensely social and emotional creatures, and so, instead of excluding emotion from its analysis and projection of symbolic structures from one area of thinking to another, it encourages emotional and social evaluation of them - and not just in dreams. Matrix Thinking takes place within a world of social and emotional validation, and offers various satisfactions of intellectual, social, and emotional types. It is its own best reward for the working scientist, artist, and theologian, as biography after biography suggests.

To summarize, we hypothesize that Matrix Thinking involves systematically bringing together, in a creative dialectic, different kinds of signs, symbolic structures, gradients, analogies, narratives, and entire paradigms, as well as processes laid bare through introspection and observation of natural phenomena. The structures can be partly or purely social and/or emotional - which would be expected for intensely social and emotional members of the genus Homo. The results are new models, new analogies, new creations that have new characteristics, which are either observed or manufactured, real or imaginary, naturally occurring or culturally invented. Matrix Thinking is a capacity that allows - indeed, among some individuals, propels - the creation of new cultural knowledge. Finally, as we will explore in the sequel to this paper, Matrix Thinking is a wellspring of new cultural knowledge for the coming Global Society, as we continue to evolve biologically and culturally at a markedly rapid rate (Cochran \& Harpending 2010). We will return in the sequel of this paper to the teaching and use of Matrix Thinking in confronting global problems.

Before we leave our section on definitions, we should address the term "sentience," which has not been used often to this point, but remains an important parameter for the existence of Matrix Thinking on Earth. We became aware that there was confusion over "sentience," and that two current meanings of the word were in common usage. One meaning emphasized sensation and perception, so that a "sentient" creature was a "sensate" creature. A second meaning focused on awareness, usually selfawareness, so a "sentient" being was a self-aware, being. The second usage is the meaning we employ. In a previous publication (Corbally \& Rappaport 2013), we distinguished "sapient” and "sentient." We chose "sentient” because archaeological evidence (beads, paints, long distance trade, and complex tools) now suggests that sentience may characterize hominins who were not yet "anatomically modern humans" (AMH) - not yet Homo sapiens sapiens - but humans that archaeologists and evolutionary biologists now often refer to as "archaic man.” It seems increasingly reasonable to use the term "human" for what seems to be a growing variety of early populations who were migrating throughout the Old World, some out of Africa, so to speak, and some perhaps back into Africa, too (Stringer 2012). DNA studies of an individual from the newly identified hominin population, the Denisovans, who lived in Spain 300,000 years ago, reveal some sequences of DNA that have never before been 
seen (Meyer 2012). The mixture of Neanderthal, AMH, and unknown DNA suggests that populations of archaic humans were interbreeding, and that there are hominin populations yet to be discovered.

One of our goals in The Human Sentience Project is to reclaim the term "sentience" for the genus Homo, so that it comes to represent the full flowering of selfconscious, self-aware intelligence in beings for whom scientific, religious, and artistic thinking is so important. This level of complexity in a Big History framework occurred on only one evolutionary line - the one that led eventually to our own species, to us, but we now understand it to be more generally characteristic of the genus Homo.

\section{THEORETICAL ORIGINS OF MATRIX THINKING}

After linking Robinson and Southgate's paper to the enhanced working memory concept of Wynn and Coolidge, it still was not clear to us how the mental processes used in a "creative dialectic" might function as a favorable biological adaptation for early humans until we delved into the archaeological literature - both traditional, and the new cognitive archaeology (De Beaune, Coolidge, \& Wynn 2009). There, we found congruent findings from experiments with children and chimpanzees (Dean et al. 2012); from excavations of ever-more-complex technologies found in ever-more-distant Middle Stone Age sites in Africa (Henshilwood, D’Errico, \& Watts 2009; Brooks et al. 2006; D’Errico, Henshilwood et al. 2005); and finally, from the questions used to test the adaptive nature of changes in cognition, which the latest generation of evolutionary biologists are finally and thankfully developing (Cochran \& Harpending 2010; Coolidge \& Wynn 2009; Fiddick \& Barrett 2001). Those test questions for cognitive domains are addressed in the sequel to this paper.

The nature of the faculty that we eventually called, "Matrix Thinking” was initiated by Robinson and Southgate's use of the term "juxtaposition” and what that might require in terms of hominin cognition. We remain convinced that juxtaposition is a key, but only one key. Matrix Thinking is not just holding two or more things in the mind without distraction (a requirement of Wynn \& Coolidge 2011). It is using comparison, contrast, and analysis to form something new from them. We call this "dynamic juxtaposition” or "operationalized juxtaposition” because it is operationalizing or projecting a type of relationship (or, at minimum, a quality) from one area of the mind to another, and the result is the creation of new cultural knowledge. This is a great deal to ask of any animal's brain, so we were drawn to works on the evolving size and complexity of the primate brain (especially the hominin brain), as are many others, including scholars in the cognitive science of religion.

Matrix Thinking gradually took form from a broad literature search on human sentience and cognition in diverse fields of the sciences and humanities: (1) archaeology, including interpretations of finds from traditional "stones and bones" excavations, as well as re-creations of ancient activities in the new cognitive archaeology; (2) psychology, 
especially cognitive psychology and the study of perceptions, but also thought experiments in the style of philosophy; (3) biology, especially the study of human evolution through natural selection, and the metamorphosis of "proper [original] functions” to “actual [today’s] functions” (Fiddick \& Barrett 2001); (4) population genetics, especially the mechanisms by which genes arise and spread, stabilize, and disappear in human populations (Pollard 2013; Cochran \& Harpending 2010); (5) cultural anthropology and the ethnological study of present-day hunter-gatherers; (6) the cognitive science of religion, a cross-disciplinary field that draws in thinkers from the physical and social sciences, as well as philosophy and theology (Van Slyke 2011); and (7) not least of all, literature, where many concepts in the sciences are first imagined. Because the development of the Matrix Thinking construct is an example of broadly interdisciplinary research, it will be useful to chronicle the most important scholars who provided antecedents from their divergent fields.

(A) The Semioticians on Movement, Process, and Change.

Preferring to avoid the creation of arcane new terms when good ones exist, we return to Robinson and Southgate to ferret out the terms that first suggested "a process." These include: "entering a semiotic matrix," "creative dialectic” (2010, 702-3), "semiotic dialectical matrix" (2010, 703), and the "juxtapositions of signs” (2010, 702). The authors use two-dimensional grids (Fig 2, 698 and Fig 3, 701) in which to generate the transposition of meaning.

We became convinced that the construct of Matrix Thinking implies dynamic mental activity, movement, and some kind of transpositions that were potentially new and different, and so, creativity. The mental processes involved in Matrix Thinking are, at minimum: comparison and contrast; identification, expansion, and transposition of analogies (structural relationships); derivation of ideal types and naming them (for ease of use and wider use); and paradigm re-structuring and stretching.

A parallel model already exists for the most basic of these processes, because the juxtaposing of language symbols is exactly what a human does every time he or she speaks grammatically (in a linguistic sense). Grammar implies the movement and coalescence of meaning within the context of an utterance, because not only the content, but the ordering of words shapes meaning. An adjective placed before or after a noun can radically alter the sense conveyed. Deacon has written extensively on this parallel or "coevolution” of language and symbol use (1997). Most combinations of words and sounds have been encountered many times before by a listener, so there is little new.

However, new combinations do arise, especially in poetry, metaphor (Robinson \& Southgate 2010, 702), and everyday speech, in order to create new ideas, structures, images, and feelings in the speaker or the listener. New creations hinge in part on the infinite re-combinability of more basic elements, as noted previously. Fully sentient humans do this easily, every day, all day long, when they think and communicate. They were born, and have evolved to juxtapose, to recombine, and to create new cultural knowledge, even if it is the re-discovery of some existing understanding, as children 
often do. There is imagination (and Matrix Thinking) in children's “re-creating the wheel” with the discovery of "new relationships" to which parents nod and smile.

Deacon, in his summary of the symbol concept, cannot help but imply movement when he discusses symbolic reference and the assignation of meaning to various kinds of signs (2011, 393-405). Something (or its quality) moves (changes position) and affects something else. Indeed, his paper begins by recalling the etymology of the word, "symbol," from the Greek ballein (to throw) and syn (together) (2011, 393). It is this kind of movement that we understand characterizes Matrix Thinking. It is the movement inherent to the notion of “a process,” whether physical or mental. It signals change.

It is important to add that our development of Matrix Thinking does not rely so much on semiotic analysis, i.e., on teasing apart the ascription of meanings to types of signs because of their functions. Instead, our paper is about applying symbolic structures, themselves (analogies, gradients, outlines, kinship systems, paradigms, even narratives and networks), to create new cultural knowledge. That is the essence of Matrix Thinking.

At the beginning of this section we note that modern human cognition goes beyond symbol use - but where does it go? Answering that question is the task at hand.

(B) Wynn and Coolidge on the Executive Functions.

In spite of the movement and finely tuned changes in meaning possible with symbol use in a specific language and culture, we were convinced that Matrix Thinking includes more than symbol use (in a linguistic sense). Wynn and Coolidge were helpful in understanding which non-linguistic faculties might also be involved, because we never assumed that Matrix Thinking was dependent on language. There was always primary process thinking to consider (Holt 2008), to which we shall return in the sequel.

In the past twenty years, it has become well accepted that modern human cognition implies more than symbol use, which is now broadly understood to exist among chimpanzees in a far more rudimentary form. Chimpanzees have been seen to make simple re-combinations of silent image-morphemes to express a request or command. Because symbol use is found in our nearest living relative, it must have been part of the hominin line before the evolutionary split leading to modern man and the modern chimpanzee. Wynn and Coolidge write:

...the modern mind is more than just an archaic mind enhanced by symbol use. It also possesses an important problem solving and planning component. In cognitive neuroscience these advanced planning abilities have been extensively investigated through a formal model known as working memory [WM] ...At its most basic, WM is the mind's ability to hold in attention, and process, task-relevant information in the face of interference (2011, 1-2). Evidence from neuroscience clearly identifies a planning and problem solving ability that is isolable neurologically and behaviorally from symbolic and language abilities. This component of modern thinking is working memory. Archaeological evidence indicates 
that human WM capacity underwent an enhancement to the modern range in the relatively recent past $(2011,9)$.

Wynn and Coolidge extend WM to Enhanced Working Memory (EWM), which includes the executive functions of planning and strategizing (2011; Coolidge \& Wynn 2009; 2001). They have used an EWM cognitive model to analyze archaeological finds and report that the "result has been a different and controversial picture of the emergence of one of the components of modern thinking" $(2011,2)$. They state that their main problem is methodological, i.e., the interpretation of archaeological evidence for working memory. "Hints at increasing capacity (beyond an ape range) can be identified as far back as Homo erectus... But when did it achieve modern levels, something we have labeled ‘enhanced working memory' (EWM)?” $(2011,4)$.

The full answer to this question must await evidence that lies hidden in the ground. Nevertheless, we suggest that Matrix Thinking could be one of the faculties that evolved in concert with working memory. Survival could be greatly enhanced by use of the executive functions of EWM, and by an ability to compare strategy options extensively using a faculty such as Matrix Thinking. For bands of humans who were dependent upon a hunting and gathering lifeway until as recently as 10,000 years ago, planning a hunt or a gathering foray would be greatly assisted by expanding a rectangular grid-like set of options to include a time dimension, thus making the mental display three-dimensional.

One of our first indications that Matrix Thinking necessarily went beyond a twodimensional grid was an attempt to extend Robinson and Southgate's example of the Christian Eucharist (2010, 698). They call the Eucharist an "iconic legisign" (the Last Supper as an icon repeatedly observed according to a conventional rule, the entire ritual symbolizing oneness with Jesus). By using a third dimension of time, we expand our understanding of the Eucharist in a three-dimensional grid displaying 2000 years of church history. The meaning and significance of the Last Supper slides forward two millenia. Our view changes. In our Extended Eucharist example, the ritual can now be viewed in the context of modern social problems and the existential needs of people in a rapidly urbanizing world of the Information Age.

The earliest indications of the Advanced Domains of Thought (science, religion, and art) - and we believe, Matrix Thinking - come from the Middle Stone Age, which lasted from about 300,000 to 30,000 years ago in Africa. Some of the most intriguing and newest archaeological finds include, for example, a purposefully prepared external storage device discovered at Blombos Cave in South Africa (Henshilwood, D'Errico, \& Watts 2009), and carefully, evenly pierced shell beads from the same site (D’Errico, Henshilwood, et al. 2005). While South Africa yielded these finds, East Africa has also recently provided indications of man's growing cognitive and symbolic capacities. Evidence from Africa includes red ochre and hematite for painting, insecticidal bedding (implying knowledge of a pharmacopeia), compound tools (implying enhanced planning 
and in-depth knowledge of construction materials), well carved flutes to play music, and evidence of long distance trading.

Together, these discoveries signal rationally, empirically grounded knowledge of the environment (science), an ability to plan and fashion specialized tools (technology), and perhaps hints of spirituality in self-adornment and music making (art), which are important components of ritual (religion). It is important to remember that the origins of religion were not the origins of "organized religion" that we see developing after the advent of agriculture around 10,000 years ago. The origins of religious thought probably appeared at the beginning of the Middle Stone Age, in the form of awe, wonder, animistic notions of spirits residing in natural places and phenomena, and symbolic attachment of meaning to supernatural phenomena of all types, as they were perceived and conceived by early members of our genus Homo.

Recall Wynn’s informal remarks in a Smithsonian Institution online blog: "Finding evidence of this kind of cognition is challenging because humans do not use advanced working memory all that much. 'It requires a lot of effort,' Wynn says. 'If we don't have to use it, we don't'” (2012). The relatively infrequent use of Enhanced Working Memory further likens it to Robinson and Southgate's "entering a semiotic matrix" in order to accomplish a creative dialectic through juxtaposition of signs - and for us, all kinds of symbolic structures - in mental space that evolved to handle complex operations. We sensed that we were approaching ever more closely the creativity that marks full sentience on the hominin evolutionary line. The fact that EWM might not be clearly found often in the archaeological record strengthens the notion of its specialness, as well as the possibility that whatever this inherited capacity is, it is an important part of man's greatest accomplishments in science, religion, and art.

The writings of Wynn and Coolidge, and Robinson and Southgate suggest faculties of human sentience that go beyond the use of symbols. Matrix Thinking may well be one type of cognition that evolved along with executive functions such as planning and strategizing, and also as an extension of the manipulation of more basic signs (the icon and index). The process of Matrix Thinking is extraordinarily flexible, given a sufficiently large brain, and it produces ideas and behaviors that can be quickly conceived and modified to suit survival needs. It is important to remember that, whatever capacity lies at the foundation of science, religion, and art, and that makes them somehow similar, it originally had to make sense in the context of natural selection. Whatever mental capacities evolved among early populations of the genus Homo, they had to confer a reproductive advantage and enhance the survival of individuals who pursued a hunting and gathering lifeway (Cosmides, Barrett, \& Tooby 2010; Stringer 2012; Fiddick \& Barrett 2001). Early on, we came to see sentience (including Matrix Thinking) as the ultimate adaptation, so far, because humans are still evolving (Cochran \& Harpending 2010; Hawks et al. 2007). 
(C) Evolutionary Scientists on the Importance of Sociability in Human Cognition.

When we began our exploration of sentience, we sampled the literatures in a wide variety of sciences and humanities to determine how other scholars described sentience and the specialness of human thought, particularly in science, religion, and art. From this broad review, we developed a list of the general components of sentience (Table 1). The features that characterize sentience in Table 1 were suggested by other authors, although their areas of research and practice were varied and they tended toward interdisciplinary endeavors. Table 1 appears very inclusive, as well it should, since these are the qualities that, together, the sciences and humanities have fastened upon to describe the essence of the human species. Sentience is not defined by any one of these characteristics or by a few of them, but by all of them at the same time. Further research led to more specialized lists for science, religion, and art (Table 2). We shall return to these more specialized lists in "tests" of science, religion, and art as true adaptations, in the sequel to this paper.

Table 1. The General Components of Sentience

- Consciousness

- Awareness

- Self-awareness

- Desire

- Will

- Personality

- Prudence

- Introspection

- Concentration without easy distraction

- Symbolic thinking

- Intelligence (intellectual, social, emotional)
- $\quad$ Social sensitivity

- Ability to anticipate intentions of others

- Insight

- Sympathy

- Empathy

- $\quad$ Social sensibility

- Charity, or values-based altruism

- Capacity to fall in love

- Ethics

- Wisdom

- Matrix Thinking

Our review of interdisciplinary sources helped us to understand how archaeologists and evolutionary biologists came to develop the next, important insight concerning the evolution of human thought. The energy burden placed upon early humans (and to a lesser extent, all members of the order Primates) by an expanding brain size required explanation. No other line of evolution has created the same degree of brain expansion. In retrospect, it seems reasonable that brains of a size and complexity that enabled them to accomplish complex manipulations of symbolic structures, to plan and strategize, and to fasten intently for extended periods upon survival problems, required a great deal of energy. Yet, evolutionary scientists ask: Why did this costly Primate brain expansion occur? What initiated the change? What kept it going? What was there about the ancient environment of early humans that made brain expansion desirable when it emerged? Some have pointed to a changing African climate and environmental stress 
(Brooks 2008). This stimulus is potentially of great importance. Another line of reasoning points to the intensely social character of the higher species in the order Primates, and explanations based on sociability are particularly cogent, interesting, and eventually directed us to an important insight about sentience on the hominin line.

We had not been ready to characterize what we eventually called Matrix Thinking - provisionally, the creative driver of human sentience - because the features of sentience that seemed to be lacking from our model were not so much in the realm of intellect and reason, but in man's fundamental sociability and his use of emotionality in vetting his rational models (“Does it feel right?”). Rational and scientific features dominate, but social and emotional features permeate all in-depth explorations of sentience, whether literary or scientific. Indeed, these features are prominent in our lists of general sentience components (Table 1). Human thinking is always social thinking, even in an individual's seemingly isolated pursuit of science, religion, or art. While it is often said that "sentience equals rationality," it is important to remember that full sentience developed on Earth only among species that were intensely social - not "social" in a preprogrammed fashion like the bees and ants or other members of the insect order Hymenoptera, but in the more plastic way characteristic of mammals, and especially species in the order Primates. Social insects and social primates are at the far, opposite ends of two major evolutionary branches, and to apply the same term "social" to both types of species' joint activities is misplaced.

Evolutionary theory reminds us that it was not the individual human who evolved. It was a population of them, in fact, an increasing number of identified populations of archaic humans in the Old World (Garrigan \& Hammer 2006; Wang, et al. 2006; Voight, et al. 2006; Trinkaus 2005; Garrigan, et al. 2005; Templeton 2005). In those breeding populations and their individual bands, the social group was, and remains today, the key to survival for the individual human, so it makes logical sense that whatever enhanced sociability was potentially adaptive. It was a type of sociability that required long periods of nurturance and learning, and varied somewhat from group to group - a feature humans share with all the anthropoid apes and to a lesser extent, with monkeys.

It may be helpful to note that there is still some debate as to whether the unit acted upon by natural selection is the individual human or the human group. While it is not our intention to explore this philosophical debate (along with a definition of "altruism" in a biological context and a discussion of the sociobiology debate), it is quite clear that the individual hominin is the one who lives or dies, and so receives the ultimate "selection" by natural selection. Yet, the human social group, with its inherent, superior capabilities when individuals act in concert according to a shared culture is, in general, acknowledged by anthropologists and evolutionary biologists as far more important than groups in other species. The human cultural group makes a critical difference in the survival of the individual. The flexibility of human culture (using biologically based features like Matrix Thinking), will ultimately be traced to physical changes that occurred in the course of hominin evolution, and eventually, the identification of specific genes and gene 
combinations. Even Matrix Thinking, if it can be demonstrated by repeated research studies (like "executive functions" of the human brain), will be traced to genome changes in human populations.

(D) Dunbar on The Social Brain Hypothesis, and Whiten and Erdal on SocioCognitive Niche.

In the decades spanning the millennium, archaeologists and evolutionary psychologists such as Richard Byrne (1995; Byrne \& Bates 2010), Nicholas Humphrey (2003; 2011), Robin Dunbar (1998; 2009), Andrew Whiten (1999; Whiten \& Erdal 2012), and Chris Stringer (2012), have confronted a major theoretical question: Why did the primate brain evolve to be so large, indeed tripling the genus Homo's encephalization in the past 2.5 million years (Whiten \& Erdal 2012, 2119)? What created sufficient selection pressure to make these enormous changes? Was total brain size really all that important? Wasn't the brain's structure more important than its size? What would make man's large brain worth the energy required to fuel it?

Evolutionary psychologist Robin Dunbar’s 1998 investigation led to a formal statement of the social brain hypothesis. He takes the reader systematically through one hypothesis after another, to arrive at conclusions that are crucial in understanding the context in which sentience first emerged on the hominin line. First, he had to find a good measure of "brain" since the size of brains varies among different sized animals. He found that the ratio of the primate brain's neocortex (where executive functions reside), to the medulla (a more primitive brain organ), increases in size steadily and linearly from lower to higher primates, including man $(1998,180)$. Second, the neocortex ratio (neocortex vs. the rest of the brain) best predicts group size in anthropoid (higher) primates: The larger the ratio, the larger the group (troop) size. Third, he successfully challenges other hypotheses about the origin of large brains (e.g., type of foraging; percentage fruit in the diet) and finds that neocortex ratio is related to mean group size at a highly significant level of $.001(1998,182)$. Dunbar refines this striking finding by methodically testing what mediates this relationship: visual signals; pattern recognition, pure memory, emotional responses, or ability to manipulate information about social relationships. He concludes, "The social brain hypothesis is about the ability to manipulate information, not simply remember it” $(1998,185)$. The nature of that manipulation has been described in scientific, humanistic, and literary writings, including those by Robinson and Southgate, and Wynn and Coolidge, among many others.

In the years since Dunbar's systematic analysis, others have paraphrased the social brain hypothesis in very informal terms, which may have some utility. The following description captures the type of sociability that we all naturally come to appreciate from birth. We take it for granted. We know it well.

Primates are not the only mammals that live in large groups, but monkeys and apes stand out...for having very intense social relationships. In fact, 
watching a group of monkeys is kind of like watching a soap opera: Individuals have friends, but they also have enemies. They team up to form coalitions to overthrow their foes, but they also reconcile after a fight. They yield to the leaders of their group, but they also sneak off to engage in clandestine affairs when no one's looking... If you're going to be involved in all of these social maneuverings, you need to be able to keep track of all sorts of social information... you need a big brain. (Smithsonian Institution Online Blog 2011).

At the same time that theorists speculate as to why sentience emerged, archaeologists and evolutionary biologists have continued the painstaking work of piecing together the details of exactly how sentience developed by examining the remnants found lying in the ground of early humans' science and technology, ritual, and art. With respect to these Advanced Domains of Thought, scientists always selfconsciously monitor themselves, asking, “Are we reading too much into this?” When we regard a carefully prepared flat surface of red ochre and see evenly spaced markings made with a sharp tool by someone between 100,000 and 70,000 years ago, is it too much to assume that the hominin thought like you and me, and was acting similarly, as when we make hatch marks on the back of an envelope to make sure we know how many times we have done something? Are we jumping to conclusions when we find carefully punctured shells whose number, precise holes, and decorative quality suggest a necklace? Is this too far to go? After all, what is so significant about making and wearing beads? The answer to such a question is the subject of a short paper for Zygon, to be sure!

Are we jumping to conclusions, or are we seeing our own behavior from farther and farther back in time? It can be a poignant experience for a modern human to realize for the first time how similar these beings were to our neighbors and our kin - that, they are we. The new field of cognitive archaeology attempts to recreate and explore the mentality that accompanied the creation of early humans' cultural artifacts and patterns of behavior (e.g., De Beaune, Coolidge, \& Wynn 2009). Long-lost techniques are rediscovered along with the mentation that accompanied their use. Is the exercise valid? What are we looking for, if not ourselves?

Evolutionary psychologists Andrew Whiten and David Erdal (2012) use an ecological framework to understand the niche separation that made early humans distinctive vis-à-vis other animals who were exploiting the same general environment. Members of the genus Homo foraged for foodstuffs and exploited available prey, thus separating themselves from other species that used different approaches to gaining sustenance. The niche separation, itself, was adaptive by making early human strategies complementary to, rather than in competition with, other species. Yet, what was so unique about early humans' actions that together qualified them for a new and separate ecological niche? Whiten and Erdal use Tooby and DeVore's concept of a "cognitive niche” $(1987,209)$ to describe early humans' "conceptually abstracting from a situation a model of what manipulations are necessary to achieve proximate goals that correlate with 
fitness.” Whiten and Erdal find that “...the concept of the hominin 'cognitive niche' really signals a new sophistication in cognitive powers, reflected in massive encephalization...” $(2012,2120)$. The use of hunting weapons and traps, sophisticated tracking, and later analysis of what took place on the hunt - all of these would illustrate the fruits of the conceptual abstraction characteristic of this ecological niche.

Whiten and Erdal go further to define early humans' "socio-cognitive niche," which depends upon cooperation; egalitarianism (sharing for the benefit of the group, the use of negotiation, and group decision-making); mindreading, theory of mind, or interpreting what others' thoughts and views are, thus enabling "the band to act as a unified, sophisticated predatory 'organism”' (2012: 2123); language; and cumulative culture that allows innovations to accrete and produce new cultural knowledge that is transmitted through the generations (2012, 2121-2126).

\section{(E) Our Perspective on the Importance of Emotionality for Sentience.}

The focus in Whiten and Erdal is not on human emotion, although the reader cannot help but imagine the emotional exchanges that must have occurred during intense social interaction of early humans while they fought for survival and exploited their socio-cognitive niche. Much attention has been paid to sociability as a foundation of sentience in early humans, and the development of rational thought is now conceived as solidly within a social matrix. However, emotionality has received less attention. There have been a few surveys of "emotion and archaeology" (e.g., Panksepp \& Biven 2012), but only recently has the emerging field of the archaeology of emotion begun to take shape. Tarlow (2012) carefully surveys models and methods for understanding emotion in the archaeological record.

As part of The Human Sentience Project, one of our goals is to explore emotionality as a basis for sentience, and as an important factor underlying the Advanced Domains of Thought. Our goal in a recent conference paper ${ }^{4}$ on "The Emotional Brain Hypothesis" is to illustrate that emotionally-informed decision making and even scientific modeling evolved to the benefit of members of the genus Homo. We view emotion, as well as sociability, as important components of Matrix Thinking, and have evaluated each general component of sentience as having intellectual, perceptual, and emotional features. [A table with this analysis is in the sequel to this paper].

The history of emotion's importance is very old indeed. Sentience took hold as man's greatest biological adaptation, and it did so in a way that meant later humans could not help but vet rational decisions, in part, through emotion. Recent findings show that problem solving proceeds best for human children when they interact as a group on all levels: social, emotional, and intellectual. Dean et al. (2012) illustrate this in a study where learning a task by human children is seen as fundamentally different from chimpanzees' efforts to accomplish the same task. Individual children are encouraged by 
each other to tinker, change, explore, and try new things. Together, human children "ratchet up" the process of creativity until a synthesis is created and a solution is found.

Human adults do this, too. Emotion is an important part of cultural ratcheting within generations, and part of scaffolding between generations (Caporael, Griesemer, \& Wimsatt 2013). When we examine our lists of specific sentience components in Table 2 , we conclude that scientific, religious, and artistic thought probably evolved in an interactive fashion, so that emotional evaluation of rational decision-making took place constantly within a social context of individuals who encouraged, supported, challenged, and argued with each other in order to arrive at a decision for the benefit of the group. This mechanism operates indirectly, too. Emotion drives the modern scientist and he uses it to feel his way toward theory. The religious practitioner helps others to meaningfully interpret emotional and spiritual experience. The modern artist re-interprets the urban landscape in light of old human emotions.

Table 2. Specific Components of Sentience for Science, Religion, and Art

Components of Sentience: Scientific Thought
Components of Sentience: Religious Thought
Components of Sentience: Artistic Thought
- Logic, and the recognition of cause and effect

- Manipulation of symbols

- Conceiving a timeline

- Recognition of empirical "facts" (even if fallacious) and assigning meaning to them

- Recognition of imperfectly similar events or objects (through comparison) and extrapolation to new cases

- Ability to form explanations

- Skepticism

- Numeric ability

- Geometric ability

- Multidimensional imaging

- Modeling and manipulating formulas

- Matrix Thinking
- $\quad$ Awe and wonder

- Belief in supernatural spirits or beings

- Adoration

- Reverence

- Obedience

- Endowing ritual with symbolic meaning

- Alignment, or continual comparison with a moral code; planning one's life according to that code

- Introspection, concentration, and meditation

- The habit of prayer

- Religious transformation, or ability to achieve a deep selflessness and be filled with a supernatural presence

- Achieving an ecstatic state (an altered state of consciousness) to interact with the supernatural

- Matrix Thinking
- $\quad$ Pleasure

- Play

- Recognition of beauty (and genetic quality) in symmetry

- Recognition of beauty (and health) in color

- Recognition of beauty (and sexual receptivity) in form

- Recognition of beauty in sound patterns

- Recognition of beauty in composition

- Recognition of beauty in asymmetry

- $\quad$ Self-correction, continual editing

- Purposeful synesthesia

- Symbolically attaching features of Art to Science and Religion

- Matrix Thinking 
(F) Pagel on the Origins of Religion, Art, Music, and Morality.

Evolutionary biologist Mark Pagel points correctly to the capacity for culture as one of the human species' defining attributes (2012). He views cultural "memes" as units that compete, just as genes compete in reproduction. This may strike many cultural anthropologists as a simplistic view of cultural evolution, perhaps rightly so, because the processes operating at the biological level are not the same as at the cultural level - that is, a specific culture held by a group of people, not a general capacity for culture, which is embedded in the species' genome. In his application of the theory of biological evolution to cultural evolution he may be running into the problem of mixing levels of complexity, which theorists in Big History are now trying hard to resolve.

Yet, Pagel does provide tantalizing suggestions by the inclusion of art, music, religion, and morality as human attributes, within the context of evolutionary science. This is not new for philosophers, but it is relatively new for evolutionary biologists, and it may mean that we are finally approaching a time when capacities such as religious and artistic thinking may be understood from the perspective of the human genome. Pagel holds that humans share a general sense of morality cross-culturally - this, in spite of differences in value systems and social control in widely different cultures. His work causes us to wonder if a cross-cultural moral sameness for the species - if one exists may indeed be the result of similar life cycle events (birth, puberty, marriage, and death), and similar processes of human cognition, such as Matrix Thinking.

Pagel writes on theories of the adaptive nature of "religion and other cultural 'enhancers"' (2012, 132ff.) and confronts issues related to the maladaptive nature of religious excesses. He addresses "possible Darwinian roles for music and visual art" (2012, 164ff.). We will return to Pagel in the sequel to this paper, with an evaluation of existing theories for the adaptive role of scientific, religious, and artistic thinking - our Advanced Domains of Thought that are the crowning achievements of human sentience, so far. We do this in an evolutionary context and apply tests for "special design."

\section{PROCESSES IN MATRIX THINKING AND EXAMPLES OF THEIR USE}

In this, our initial effort to explicate the construct of Matrix Thinking, we will define the mechanics that are suggested by phrases such as "creative dialectic" and our own "operationalized juxtaposition." Here, we define a matrix for Matrix Thinking, and then summarize the processes that take place within the matrix, and give examples.

\section{(A) Defining the Matrix.}

The matrix used for Matrix Thinking is a mental representation that facilitates extended interaction of its structural components. The best way to visualize a matrix can vary for individuals, although a two-dimensional rectangle is a good place to start. They are useful with two provisos. First, on a flat sheet of paper or a flatscreen, matrices have 
two dimensions, and as we have seen in the case of the Extended Eucharist example above, three dimensions are sometimes useful. Indeed, as many dimensions as necessary can be used in Matrix Thinking, although four dimensions are often challenging. In Stephen Hawking's A Brief History of Time, the reader is helped to imagine four dimensions (three spatial, one temporal) with cones, diagrams, and cartoons. Yet, three spatial dimensions and one time dimension can be difficult for many to manipulate, although some people do this every day. Three spatial dimensions are more easily pictured, as in computer-assisted design programs and genome research programs in which 3D structures can be seen rotating on a flatscreen. On flat paper, three dimensions are often diagrammed with $\mathrm{x}, \mathrm{y}$, and $\mathrm{z}$ dimensions. Several commonly used statistical packages such as SAS provide easy access to three and four dimensions for those who have a sizable database and can accomplish relatively easy programming operations. For example, multi-dimensional scaling, factor analysis, and canonical correlation routines can provide a good feel for third and fourth dimensions of variation in a database. Nevertheless, most of the examples used here are in two dimensions, for easy illustration.

A second proviso is that the symbolic structures that are, for example, applied to a new topic in Matrix Thinking are not always in rectangular form, themselves. In the Fictive Kinship example, above, an entire kinship structure (frequently diagramed in a tree branch or root pattern) is held up to a new instance (a man lost and hurt), and a place is found for this lone individual in an existing kinship structure. His new position is perhaps determined according to his characteristics, or who in the group is in need of assistance from a man that is usually provided by kin (for example, marriage, housebuilding, or sustenance). No doubt informal factors also play a role (who likes him and who he likes). Afterward, because he is then embedded in the kinship structure, itself, he has to abide by its rules henceforth. Placement of him is a stellar example of the flexibility of cultural structures and their rules. Few groups can afford to waste an adult man or woman.

Similarly, Matrix Thinking can handle networks, holding up a network example to a new instance. For example, an epidemiological network of disease transmission, with Patient Zero at the center of a network with a certain network density and intensity of contacts, can be held up to a new outbreak of disease. Analysis helps to determine where to focus a prevention program. Matrix Thinking can be used for very practical purposes, and is, in fact, used every day in program evaluation and policy analysis.

The matrix, itself, in Matrix Thinking is a mental construct that is either implicit or explicit, and which provides a framework for comparison, contrast, extrapolation, and the creation of new cultural knowledge.

Let us now turn to a relatively simple example of Matrix Thinking in the creation of a new metaphor. In Table 3, an example of metaphor generation appears in a $1 \times 3$ rectangular grid with a top row of labels. In the left cell, the original metaphor is displayed. Its words are few, but when de-compressed in the center cell, it has a fascinating meaning and clear structure. Some of the artistic satisfaction of the metaphor 
comes from its compressed nature, and unpacking the metaphor in the middle column takes some delight from it. Nevertheless, it provides a good opportunity to examine its structure and meaning, and to create the parallel metaphor (perhaps not quite so elegant), displayed in the right column. De-compression is akin to explication de texte, a type of structural analysis in French literature. In Table 3, a structure is laid bare and used to stamp out another, similar (although not exact) instance by searching for words and idioms in the toolkit of the English language. The second metaphor is an example of the creation of new culture.

Table 3. Matrix Thinking and New Metaphor Construction

Original Metaphor

"His fine wit makes such a wound that the knife is lost in it.”

\section{De-compression of the Original Metaphor's Logic}

\section{Creation of a New Metaphor with a Similar Structure}

$\begin{array}{ll}\begin{array}{l}\text { A fine wit is often called a "sharp } \\ \text { wit.” }\end{array} & \begin{array}{l}\text { "The old crow's barbed } \\ \text { tongue gets tangled on the } \\ \text { A knife is sharp. }\end{array} \\ \text { A sharp knife can cause a wound. } & \text { fibers." } \\ \text { Wounds are physical or mental. } & \\ \text { His wit is so good that it can create a } \\ \text { wound of sufficient size and depth } \\ \text { that a knife becomes lost in it. } \\ \text { His wit is so clever that in spite of its } \\ \text { sharpness and the wound it might } \\ \text { cause, it loses its destructive edge } \\ \text { because of the very size (or other } \\ \text { quality) of the wound itself. } \\ \text { The cleverness of the speaker is } \\ \text { apparent, and no one is badly } \\ \text { wounded. }\end{array}$

A fine wit is often called a "sharp

wit."

A knife is sharp. His wit is so good that it can create a wound of sufficient size and depth that a knife becomes lost in it. His wit is so clever that in spite of its destive edge cause, it loses its destructive edg The cleverness of the speaker is wounded.

Because our work is never far from trying to understand human capacities in a context of evolution and natural selection, we should take this opportunity to examine Robinson and Southgate's words on Neanderthals, in which they speculate that Neanderthals had an ability to imitate "the products of this [creative] dialectic... without ever 'getting' the cognitive trick” $(2010,702)$. It is quite possible that Neanderthals or some other collateral population of early hominins, could not, for example, understand the cognitive steps in deconstructing a metaphor and creating a new one (creation of new non-material culture). For example, in Piers Anthony's 2010 novel, Climate of Change, he shows behaviorally modern early humans reacting time and again to climate change, just as archaeologists suggest. He also shows their using a method for making clothes with a sharp instrument called an awl (lacing ties through holes, or sewing). He then shows Neanderthals copying the inventions of behaviorally modern humans. Did this 
happen? Did this happen in reverse (transmission from Neanderthal to modern humans)? A critical role for archaeologists is to develop methods for the sometimes difficult assessment of when a site shows original use of a faculty and when it shows copying. This will be extremely important in determining when cultural modernity - along with its "cognitive bag of tricks" - appeared, and how its spread.

(B) Identifying Processes Used in the Matrix.

To this point, we have suggested several types of processes that are used in Matrix Thinking. Other authors suggest some of these in their own work, for example, processes similar to Reich's theory of relational and contextual reasoning (Teske 2003), and the model of Conceptual Blending identified by Fauconnier and Turner (2002).

Here, we will summarize these creative cognitive processes. In doing so, it is important to keep two issues constantly in mind: first, that our original interest was in finding commonalities that underlie the Advanced Domains of Thought (science, religion, and art); and second, these cognitive processes had to be useful to early humans who followed a hunting and gathering lifeway. Each process must be viewed as an aide in finding purchase on the enormous task of surviving. If the process cannot be imagined as having a purpose in that lifestyle, then it would have to be viewed as derivative (not bad, just not quite so basic).

The processes we suggest include: comparison, contrast, drawing two-way and multi-way analogies, developing ideal types, naming the results, and ultimately paradigm-stretching. We suggest an overall process that systematically brings together, in a creative dialectic, different kinds of signs, symbolic structures, gradients, analogies, narratives, and entire paradigms, and applies them (either singly or in combination) to new material. What kind of material? Anything or any process laid bare through introspection and/or observation of natural phenomena. All of the components of Matrix Thinking can be imaginary, as in the pantheon of Greek gods and goddesses, although there are most often some connections to real problems that humans and their societies confront. What kind of symbolic structures are compared or applied? All kinds: structures of people, ideas, colors, or even emotions. The structures can be partly, or purely social and emotional. Indeed, structures colored by emotions and social relationships would be expected for intensely social and emotional members of the genus Homo. What are the results of Matrix Thinking? The results are new models, new analogies, new creations that have new characteristics, which are either observed or manufactured, real or imaginary, naturally occurring or culturally invented. Our "Advanced Domains of Thought” (science, religion, and art) are all deeply human enterprises, which all draw upon not just intellectual and cognitive knowledge of the world, but evaluation of social and emotional factors, as well.

(C) Examples of Matrix Thinking.

Our first examples of Matrix Thinking were developed as short, five-minute dramatic presentations ("skits"), with two performers, to illustrate Matrix Thinking for 
our colleagues at a conference on astronomy and the arts. True to our two major fields (anthropology and astronomy), we developed skits on the appearance of three supernovae (unpredictable astronomical events) in A.D. 1054, 2054, and 3054, and how they were integrated into existing cultures, at three time points, each a thousand years apart.

The A.D. 1054 supernova was recorded by Chinese astrologers (the astronomers of their time) and called a "Guest Star." It remained visible to the naked eye for two years, during day and night. After the discovery of the telescope, this star was identified as the beautiful Crab Nebula, which is still expanding but no longer shines bright enough to be seen in the day because it has lost energy in almost a thousand years. In the skit, the head of the Astronomical Bureau, Yang Weide, spies the Guest Star and records his prognostications associated with it, according to a coherent structure of astrological houses, movements, and beliefs. The Guest Star was integrated into a well developed system that was politically significant, because Yang Weide apparently struggled with his prognostication for two months before explaining the appearance of the Guest Star to Emperor Renzong of Song. He made a flattering report out of what was essentially an ominous appearance.

The A.D. 2054 and 3054 skits were necessarily science fiction (whose writing is an avocation for one of us). The 2054 supernova was of Eta Carinae, which is known now to have rather unstable features. The two characters in the skit are astronomers, who have developed a short list of unstable stars that might "go supernova." They use five available telescopes to survey all of them, from an observatory on the Atacama Desert of highland Chile. One of the stars, "Eta Car,” blows, and Henry Yang (a descendant of the Yang in A.D. 1054) gains fame and a Nobel prize for capturing the data before a major supernova appears, thus enabling him to build a scientific model for why stars explode. Henry and his colleague, Xiao-Xing ("morning star"), neatly fit their understanding of the Eta Car supernova into their existing scientific culture of 2054, which is not too far off.

The A.D. 3054 skit was so far in the future, we had to use a technology that does not exist now, and for which there are significant scientific problems in development. Borrowing from the Star Trek series, we chose "sub-space communications," i.e., communication signals travelling at faster than light speed. In the 3054 scenario, an anthropologist doing field work on Europa, one of Jupiter's moons, discovers that the astronomers on Europa have found a new supernova in the constellation Cassiopeia. The anthropologist quickly contacts her astronomer-friend on Earth's Moon, to warn him that in just a few minutes, he would catch the light from the explosion of "Rho Cas." Her subspace call comes just in time, and he is able to train his lunar telescope in the right direction to catch the initial explosion. This was possible only because the sub-space call was travelling at a speed faster than the light coming in from Rho Cas. In this way, it can be shown that Matrix Thinking can be accomplished with cultures and technologies that do not yet exist, but like the pantheon of Greek gods, live only in our imagination. 


\section{CONCLUSIONS ABOUT MATRIX THINKING}

We met at the interdisciplinary boundaries of anthropology and astronomy, biology and theology, with a common interest originally in the evolutionary origins of religious thought. Later, as individuals who are religious, as well as scientists, as well as artists (of various kinds), we pursued our joint conviction that there was a sameness underlying all of our endeavors, especially when we pushed ourselves (or were pushed) to perform, or investigate, or worship with full, sentient consciousness, and toward the limits of our abilities. It was with surprise and great delight that we found an enormous, interdisciplinary literature on human sentience, and in that body of thought, scholars were working toward a conceptualization of the special mechanisms that lie at the foundation of cultural creativity. We found that researchers in evolutionary biology and psychology, archaeology, the cognitive science of both art and religion, philosophy, linguistics, and literature were, together, targeting and coming very close to a set of mental processes that allow and encourage humans to be creative, and reward them for it, not just at the limits of their abilities, but in everyday activities, as well. Because it is a derivative of our seminal thinkers Robinson and Southgate's “entering a semiotic matrix," we call this set of mental processes Matrix Thinking.

\section{LOOKING TOWARD THE SEQUEL}

In a second article on Matrix Thinking, we systematically test the three, cognitive Advanced Domains of Thought (science, religion, and art) with questions derived from evolutionary biology, especially Fiddick and Barrett (2001), and Cosmides and Tooby (2013). We also tease apart the general components of sentience (Table 1) to examine their cognitive, perceptual, and emotional features. Unsurprisingly, many of the components have all three. Finally, we apply the concept of Matrix Thinking to needs for the coming Global Society, and ask whether Matrix Thinking should be formally encouraged, and if so, how it can aid students to be better citizens. Our examples draw on our major fields of anthropology and astronomy, and we give details on the creation of new cultural knowledge through dynamic juxtaposition (Matrix Thinking) by one prehistoric and one modern culture.

\section{NOTES}

${ }^{1}$ The Human Sentience Project $\odot$ looks for answers to the question, "What is so special about the way humans think?” The Project is interdisciplinary, addressing fundamental questions at the intersection of science and religion. Yet, it relies fully on the latest findings in the social and physical sciences. Our goals are to (a) develop new formats and innovative approaches for education of youth, adults, and the public, including, for 
example: dramatic skits, interpretive dialogues, video presentations, web-based materials, and workbooks; (b) provide public education on common questions about evolutionary science and religion, and how to reconcile existing conflicts in the minds of many; (c) engage in public speaking, in order to generate good discussion among individuals from a wide variety of disciplines who share an interest in human sentience and its origins; and (d) to pursue research and analysis of existing evidence for human sentience in the archaeological record, as well as evidence from laboratory testing in cognitive psychology, cognitive archaeology, and the cognitive study of religion.

${ }^{2}$ The taxonomic classification of the genus Homo changes with new genetic and archaeological findings. Modern humans and their ancestors are referred to by either of two terms: hominid (traditional classification) and hominin (new classification). Hominin is fast becoming the preferred term, and so we have adopted that term for this paper.

${ }^{3}$ Several terms are used by archaeologists and biologists to signal "modern thinking." Among these are "cultural modernity" and "behavioral modernity." Increasingly, scholars are referring to "the external storage of symbols" as the key indicator, whether it is on incised ochre or in the organization of a campsite or in a complex tool.

${ }^{4}$ Rappaport, Margaret Boone, and Christopher J. Corbally, SJ. "The Emotional Brain Hypothesis: Emotional, Social, and Religious Vetting in the Evolution of Rational Decision Making and Scientific Modeling,” a paper delivered at the May 2014 conference of the European Society for the Study of Science and Theology, Assisi, Italy.

\section{REFERENCES}

Anthony, Piers. 2010. Climate of Change. New York: Tor Books.

Brooks, Alison S. 2008. Background to 'Out of Africa 3’: Behavior and environmental change in the Middle Stone Age," online, http://www.earthmeasure.com/pdf/Brooks.pdf.

Brooks, Alison S., Lisa Nevell, John E. Yellen, and Gideon Hartman. 2006. "Projectile technologies of the African MSA: Implications for modern human origins. In Transitions before the Transition: Evolution and Stability in the Middle Paleolithic and Middle Stone Age, ed. Erella Hovers and Steven L. Kuhn, pp. 233-255. New York: Springer.

Byrne, Richard W. 1995. The Thinking Ape: Evolutionary Origins of Intelligence. Oxford and New York: Oxford University Press.

Byrne, Richard W., and Lucy A. Bates. 2010. "Primate social cognition: Uniquely primate, uniquely social, or just unique?” Neuron 65: 815-30. 
Caporael, Linnda R., James R. Griesemer, and William C. Wimsatt, Eds. 2013.

Developing Scaffolds in Evolution, Culture, and Cognition. Vienna Series in Theoretical Biology. Cambridge: MIT Press.

Chimpanzee Sequencing and Analysis Consortium [CSAC]. 2005. Initial Sequence of the Chimpanzee Genome and Comparison with the Human Genome. Nature 437: 69-87.

Cochran, Gregory, and Henry Harpending. 2010. The 10,000 Year Explosion: How Civilization Accelerated Human Evolution. New York: Basic Books.

Coolidge, Frederick L., and Thomas Wynn. 2009. The Rise of Homo sapiens; The Evolution of Modern Thinking. Hoboken, NJ: Wiley-Blackwell. . 2001. "Executive functions of the frontal lobes and the evolutionary ascendancy of Homo sapiens," Cambridge Archaeological Journal 11: 255-260.

Corbally, Christopher J., and Margaret Boone Rappaport. 2013. "Crossing the Latest Line: The Evolution of Religious Thought as a Component of Human Sentience.” In Evolution: Development within Big History, Evolutionary and World-System Paradigms, Yearbook, eds. Leonid E. Grinin and Andrey. V. Korotayev, 197-218. Volgograd: Uchitel Publishing.

Cosmides, Leda, and John Tooby. 2013. "Evolutionary psychology: New perspectives on cognition and motivation.” Annual Review of Psychology 64:201-229.

Cosmides, Leda, H. Clark Barrett, and John Tooby. 2010. “Adaptive Specializations, Social Exchange, and the Evolution of Human Intelligence.” Proceedings of the National Academy of Sciences 107(Supplement 2):9007-9014.

Deacon, Terrence W. 2011. “The Symbol Concept.” In The Oxford Handbook of Language Evolution, Kathleen R. Gibson and Maggie Tallerman, eds. Oxford and New York: Oxford University Press. 2003. "The Hierarchic Logic of Emergence: Untangling the Interdependence of Evolution and Self-Organization.” In Evolution and Learning: The Baldwin Effect Reconsidered, ed. B. H. Weber and D. J. Depew, 273-308. Cambridge: MIT Press. . 1997. The Symbolic Species: The Co-Evolution of Language and the Brain. New York: W.W. Norton.

Dean, Lewis G., R. L. Kendal, S. J. Schapiro, B. Thierry, and K. N. Laland. 2012. "Identification of the Social and Cognitive Processes Underlying Human Cumulative Culture.” Science 335:1114-1118.

De Beaune, Sophie A., Frederick L. Coolidge, and Thomas Wynn, Eds. 2009. Cognitive Archaeology and Human Evolution. New York: Cambridge University Press.

D’Errico, Francesco, Christopher S. Henshilwood, M. Vanhaeren, and K. van Niekerk. 2005. "Nassarius kraussianus Shell Beads from Blombos Cave: Evidence for Symbolic Behavior in the Middle Stone Age.” Journal of Human Evolution 48:3-24. 
Dunbar, Robin. 2009. The Social Brain Hypothesis and Its Implications for Social Evolution. Annals of Human Biology 36(5): 562-572. . 1998. The Social Brain Hypothesis. Evolutionary Anthropology 6:178-

190.

Evans, P. D., S. L. Gilbert, et al. 2005. Microcephalin, a Gene Regulating Brain Size, Continues to Evolve Adaptively in Humans. Science 309(5741): 1717-1720.

Evans, P. D., N. Mekel-Bobrov, et al. 2006. Evidence That the Adaptive Allele of the Brain Size Gene Microcephalin Introgressed into Homo sapiens from an Archaic Homo Lineage. Proceedings of the National Academy of Sciences 103(48): 18178.

Fauconnier, Gilles, and Mark Turner. 2002. The Way We Think: Conceptual Blending and the Mind's Hidden Complexities. New York: Basic Books.

Fiddick, Laurence, and H. Clark Barrett. 2001. "Evolution of Cognition: An Adaptationist Perspective.” In International Encyclopedia of the Social and Behavioral Sciences, ed. N. J. Smelser and P. B. Baltes, 4996-5000.

Garrigan, Daniel, Zahra Mobasher, Sarah B. Kingan, Jason A. Wilder, and Michael F. Hammer. 2005. "Deep Haplotype Divergence and Long-Range Linkage Disequilibrium at Xp21.1 Provide Evidence That Humans Descend from a Structured Ancestral Population.” Genetics 170:1849-1856.

Garrigan, Daniel, and Michael F. Hammer. 2006. "Reconstructing Human Origins in the Genomic Era.” Nature Reviews-Genetics 7:669-680.

Hawking, Stephen. 1998. A Brief History of Time. New York: Bantam.

Hawks, John, Eric T. Wang, Gregory M. Cochran, Henry C. Harpending, and Robert K. Moyzis. 2007. "Recent Acceleration of Human Adaptive Evolution." Proceedings of the National Academy of Sciences 104(52):20753.

Henshilwood, Christopher S., Francesco D’Errico, and I. Watts. 2009. "Engraved Ochres from the Middle Stone Age Levels at Blombos Cave, South Africa." Journal of Human Evolution 57:27-47.

Holt, Robert R. 2008. Primary Process Thinking: Theory, Measurement, and Research. Lanham, MD: Jason Aronson, Inc., an imprint of Rowman \& Littlefield. Kindle Edition.

Humphrey, Nicholas. 2011. Soul Dust: The Magic of Consciousness. Princeton: Princeton University Press.

New York: Oxford University Press.

. 2003. The Inner Eye: Social Intelligence in Evolution. Oxford and

Meyer, Matthias, Martin Kircher, Marie-Theres Gansauge, et al. 2012. "A High-

Coverage Genome Sequence from an Archaic Denisovan Individual.” Science 338: 222226.

Mithen, Steven. 1996. The Prehistory of the Mind: The Cognitive Origins of Art and Science. London: Thames and Hudson Ltd. 
Pagel, Mark. 2012. Wired for Culture; Origins of the Human Social Mind. New York: W.W. Norton \& Company.

Panksepp, Jaak, and Lucy Biven. 2012. The Archaeology of Mind: Neuroevolutionary Origins of Human Emotions. New York: W. W. Norton \& Company.

Peirce, Charles S. 1931-1935. The Collected Papers of Charles Sanders Peirce. Vols. IVI. Charles Hartshorne and Paul Weiss, eds. Cambridge: Harvard University Press.

Pollard, Katherine S. 2013. “What Makes Us Different?” Scientific American 22 (Special Collector’s Edition 1):30-35.

Robinson, Andrew. 2010. God and the World of Signs: Trinity, Evolution, and the Metaphysical Semiotics of C.S. Peirce. Leiden: Brill.

Robinson, Andrew, and Christopher Southgate. 2010. “'Semiotics as a Metaphysical Framework for Christian Theology.” Zygon: Journal of Religion and Science 45:689-712.

Simpson, Jeffry A., and Lorne Campbell. 2005. Methods of Evolutionary Sciences.” In The Handbook of Evolutionary Psychology. David M. Buss, Ed. Hoboken, NJ: Wiley.

Smithsonian Institution Online Blog, Hominid Hunting. 2011. "Humans Evolved Big Brains to Be Social?” October 31. Web address:

http://blogs.smithsonianmag.com/hominids/2011/10/humans-evolved-big-brains-to-besocial/

Stringer, Chris. 2012. Lone Survivors: How We Came to Be the Only Humans on Earth. New York: Times Books, Henry Holt and Company.

Tarlow, Sarah. 2012. The Archaeology of Emotion and Affect. Annual Review of Anthropology 41:169-85.

Templeton, Alan R. 2005. “Haplotype Trees and Modern Human Origins.” Yearbook of Physical Anthropology 48:33-59.

Teske, John A. 2003. “Varieties of Reasoning: Assessing Adequacy.” Zygon: Journal of Religion and Science 38:441-449.

Tooby, John, and Irven DeVore. 1987. "The Reconstruction of Hominid Behavioral Evolution through Strategic Modelling.” In The Evolution of Human Behavior: Primate Models, ed. W. G. Kinzey, 183-227. New York: SUNY Press.

Trinkaus, Eric. 2005. “Early Modern Humans.” Annual Review of Anthropology 34:207230.

Van Slyke, James A. 2011. The Cognitive Science of Religion. Burlington, VT: Ashgate Publishing.

Voight, Benjamin F., Sridhar Kudaravalli, Xiaoquan Wen, Jomathan K. Pritchard. 2006. “A Map of Recent Positive Selection in the Human Genome.” PLoS Biology 4(3):e72.

Wadley, Lyn. 2001. What is Cultural Modernity? A General View and a South African Perspective from Rose Cottage Cave. Cambridge Archaeological Journal 11: 201-221. 
Wadley, Lyn, Christine Sievers, Marion Bamford, et al. 2011. Middle Stone Age Bedding Construction and Settlement Patterns at Sibudu, South Africa. Science 334: 1388-1391.

Wang, Eric T., Greg Kodama, Pierre Baldi, and Robert K. Moyzis. 2006. "Global Landscape of Recent Inferred Darwinian Selection for Homo sapiens.” Proceedings of the National Academy of Sciences 103:135-140.

Whiten, Andrew. 1999. "The evolution of deep social mind in humans.” In The Descent of Mind; Psychological Perspectives on Hominid Evolution, eds. M. Corballis and S. E. G. Lea. Oxford and New York: Oxford University Press, 173-193.

Whiten, Andrew, and David Erdal. 2012. "The Human Socio-cognitive Niche and Its Evolutionary Origins.” Philosophical Transactions of the Royal Society B:2119-2129.

Wynn, Thomas. 2012. Informal Remarks. In "When Did the Human Mind Evolve to What It Is Today?” Smithsonian Institution Online Blog, Hominid Hunting. June 26. Web address: http://www.smithsonianmag.com/science-nature/When-Did-the-Human-MindEvolve-to-What-It-is-Today-160374925.html

Wynn, Thomas, and Frederick L. Coolidge. 2011. "The Implications of the Working Memory Model for the Evolution of Modern Cognition.” International Journal of Evolutionary Biology:1-12. 